\title{
Parental hypercholesterolemia and family medical history as predictors of hypercholesterolemia in their children
}

\author{
Jorge A. Robledo, Ph.D. ${ }^{a}$, Leonardo J. Siccardi, B.S. ${ }^{a}$, Liliana M. Gallindo, Ph.D. ${ }^{b}$ \\ and Shrikant I. Bangdiwala, Ph.D. ${ }^{c}$ \\ Collaborators: Jimena Colombero, M.D. and Daniela Giorgi, B.S.
}

\section{ABSTRACT}

Introduction. Parental hypercholesterolemia would be a better predictor of hypercholesterolemia than family medical history in children.

Objectives. To compare the strength of association and predictive values of parental hypercholesterolemia versus a positive family history in pediatric hypercholesterolemia.

Material and methods. Cross-sectional, analytical study. Cholesterol levels were measured in children aged $\geq 6$ and $<12$ years and in their biological parents. A survey was administered to parents.

The association was estimated using the odds ratio (OR), and its predictive value was determined. The relationship between hypercholesterolemia in parents and their children was studied with multilevel regression. Results. A total of 332 children, 304 mothers, and 206 fathers were assessed. A cholesterol level $\geq 240 \mathrm{mg} / \mathrm{dL}$ in one or both parents and $\geq 200 \mathrm{mg} / \mathrm{dL}$ in children showed: $\mathrm{OR}=6.40$; $95 \%$ confidence interval $(\mathrm{CI})=2.85-14.48$; $p<0.0001$; sensitivity $=69 \%$; specificity $=74 \%$; positive predictive value $(\mathrm{PPV})=34 \%$; negative predictive value $(\mathrm{NPV})=93 \%$; positivelikelihood ratio $(\mathrm{LR}+)=2.69$; negative likelihood ratio $(\mathrm{LR}-)=0.42$. Family medical history versus children with cholesterol level $\geq 200$ showed: $\mathrm{OR}=1.86 ; 95 \% \mathrm{CI}=0.84-4.11 ; p=0.1272$; sensitivity $=69 \%$; specificity $=46 \%$; PPV $=19 \%$; $\mathrm{NPV}=89 \% ; \mathrm{LR}+=1.27 ; \mathrm{LR}-=0.68$. Cholesterol was 2.9 and $2.5 \mathrm{mg} / \mathrm{dL}$ higher per every $10 \mathrm{mg} / \mathrm{dL}$ of increased cholesterol in mothers and fathers, respectively.

Conclusions: Parental hypercholesterolemia was significantly associated with hypercholesterolemia in children and showed a higher predictive power than a positive family medical history.

Key words: hypercholesterolemia, child, screening, family medical history.

http:/ / dx.doi.org/10.5546/ aap.2019.eng.41

Contimedios S. A primary schools of Jovita, Química Marcos Juárez, and local farmers.

Conflict of interest: None.

Received: 2-15-2018 Accepted: 7-30-2018

To cite: Robledo JA, Siccardi LJ, Gallindo LM, Bangdiwala SI. Parental hypercholesterolemia and family medical history as predictors of hypercholesterolemia in their children. Arch Argent Pediatr 2019;117(1):41-47.

\section{INTRODUCTION}

The observation of atherosclerosis in the autopsies of young soldiers who died in the Korean War in 1953,1,2 and the confirmation of this finding in other studies, ${ }^{3-5}$ brought about a paradigm shift and it was agreed that this disease starts in childhood.

In 1983, the Lipid Research Clinics Coronary Primary Prevention Trial provided strong evidence that hypercholesterolemia was an important factor of cardiovascular risk, ${ }^{6,7}$ and early detection was recommended. In Argentina, the prevalence of childhood hypercholesterolemia is 6-15\% and that of slightly elevated cholesterol level, $15-35 \%$. $^{9-11}$

The 1998 and 2011 consensuses by the American Academy of Pediatrics (AAP) ${ }^{12,8}$ and the 2005 consensus by the Argentine Society of Pediatrics (Sociedad Argentina de Pediatría, SAP) respectively recommend, as a selective screening strategy, the measurement of cholesterol levels in children with a positive family medical history (FMH) or an unknown history of early cardiovascular conditions in their parents and grandparents or of hypercholesterolemia in their parents. In its consensus on the management of dyslipemias in pediatrics, the SAP recommends the universal screening in children aged 6 to 11 years but its mass use and costs complicate its implementation. ${ }^{14}$
A previous study ${ }^{15}$ did not find a very strong association between a positive FMH and hypercholesterolemia and diagnostic tests with acceptable values, but 
the positive predictive value (PPV) was very low due to the large number of false positive results. A strong association was also observed between hypercholesterolemia in parents and their children when both parents had hypercholesterolemia, although the sample size was small.

The objective of this study was to compare the strength of association and the predictive values of parental hypercholesterolemia versus a positive FMH in pediatric hypercholesterolemia.

\section{MATERIAL AND METHODS}

This was a cross-sectional, analytical study. The field work took place between February and June 2015. Parents' and children's first and last names, national identity document (ID), date of birth, and sex were recorded, and the anonymity of these data was maintained.

\section{Child population}

Children attending the only two primary schools (both public) at Jovita, province of Córdoba, Argentina.

Inclusion criteria: Schoolchildren attending first through sixth grade, aged 6.0 to 11.9 years as of June $30^{\text {th }}, 2015$. Informed consent signed by the mother, father or legal guardian.

Exclusion criteria: Having an infectious disease at present or within 20 days before blood samples were drawn for biochemical testing. ${ }^{16}$ The presence of chronic conditions that cause or may cause marked alterations of lipid metabolism. ${ }^{17}$

\section{Parent population}

Inclusion criteria: Being a biological mother or father and having signed the informed consent.

Exclusion criteria: Having an infectious disease at present or within 20 days before blood samples were drawn for biochemical testing. ${ }^{16}$

\section{OUTCOME MEASURES \\ Cholesterol level}

Blood drawn by venipuncture after a 10 -hour fasting period was used. Total cholesterol level was measured using the enzymatic AA liquid Colestat method (Wiener Lab). Serum was separated in the first hour following the blood draw, and tests were done in the same day using a CM250 autoanalyzer (Wiener Lab).

The technique used to measure cholesterol levels was subjected to a traceability control through the Reference and Standardization Lab for Clinical Biochemistry (Laboratorio de Referencia y Estandarización en Bioquímica Clínica, LARESBIC) of the Argentine Biochemistry Foundation (Fundación Bioquímica Argentina), and the corresponding certificate was obtained from the Cholesterol Reference Method Laboratory Network (Centers for Disease Control [CDC], Atlanta, USA).

Reference values used for children were those proposed by the $\mathrm{AAP}^{12}$ and the SAP, ${ }^{14}$ and for adults, those established by the Adult Treatment Panel III (ATP III) ${ }^{18}$ (Table 1). Cholesterol level was categorized into $\mathrm{A}, \mathrm{B}$, and $\mathrm{C}$ elsewhere in the document.

Predictive outcome measure no. 1: Hypercholesterolemia in one or both parents. This was recorded as a dichotomous outcome measure. Positive paternal or maternal hypercholesterolemia: one or both parents with a cholesterol level $\geq 240 \mathrm{mg} / \mathrm{dL}$. Negative: $<240 \mathrm{mg} / \mathrm{dL}$.

Output variable: Hypercholesterolemia in the child. This was recorded as a dichotomous outcome measure. Positive: a child with a cholesterol level $\geq 200 \mathrm{mg} / \mathrm{dL}$. Negative: $<200 \mathrm{mg} / \mathrm{dL}$.

\section{Family medical history}

It was collected through a survey designed based on the recommendations of the AAP expert panel. ${ }^{8}$ FMH was considered positive when cardiovascular, brain, and upper or lower limb diseases were detected in the parents or grandparents at an early age, i.e., before 55 years old in men and before 65 years old in women, or when the cholesterol level was found to be $\geq 240 \mathrm{mg} / \mathrm{dL}$ in the parents.

TABLE 1. Cholesterol level reference values for children and adults

\begin{tabular}{cccc}
\hline Category & Cholesterol level & Children (AAP-SAP) & Adults (ATP III) \\
\hline A & High & $\geq 200 \mathrm{mg} / \mathrm{dL}$ & $\geq 240 \mathrm{mg} / \mathrm{dL}$ \\
B & Borderline high & $170-199 \mathrm{mg} / \mathrm{dL}$ & $200-239 \mathrm{mg} / \mathrm{dL}$ \\
C & Desirable & $<170 \mathrm{mg} / \mathrm{dL}$ & $<200 \mathrm{mg} / \mathrm{dL}$ \\
\hline
\end{tabular}

AAP: American Academy of Pediatrics; SAP: Argentine Society of Pediatrics; ATP III: Adult Treatment Panel III. 
Predictive outcome measure no. 2: Positive FMH. This was recorded as a dichotomous, positive and negative outcome measure.

\section{Ethical considerations}

The approval of the Ethics Committee, the school principals, and the Ministry of Education of the province of Córdoba was obtained. All communications were conducted through the schools. Result reports were delivered to parents in sealed envelopes. Study participants' confidentiality was warranted.

\section{Statistical considerations}

Collected data were electronically stored in tabular format in Access.

The association between hypercholesterolemia in parents and their children was assessed. Paired data contingency tables were used (child and his/ her respective mother and / or father); the strength of the association was estimated using the odds ratio (OR) and its statistical significance was assessed using McNemar's version of the $\chi^{2}$ test, with a significance level of 0.05 .

The criteria implemented to classify parents and children for this analysis, based on their cholesterol level, are shown in Table 2.

The association between a positive FMH and hypercholesterolemia in children was assessed in the same manner as for the previous item.

The following diagnostic tests were done to assess the potential prediction of parental hypercholesterolemia and positive FMH in relation to hypercholesterolemia in children: sensitivity, specificity, PPV, negative predictive value (NPV), and positive and negative likelihood ratios (LR+ and LR-). The percentage of the population to be assessed (PPA) was estimated, which is the result of dividing the number of individuals to be assessed using the predictive outcome measure by the total number of assessed individuals.

The prevalence of blood cholesterol in each child and adult category and descriptive statistics of cholesterol level and age were estimated.

A multilevel regression analysis was done taking the family unit as a cluster, with a random intercept per family to consider the correlation in the response outcome measure among the members of the same family.

A sample size of 328 participants was estimated to detect a difference of at least $15 \%$ between both groups. The proportion of subjects in the exposed group (children with hypercholesterolemia) was $45 \%$ and, in the group without exposure, $30 \%$, with a power of $80 \%$ and an alpha error of $5 \%$ (Epi Info 7.0).

\section{RESULTS}

In a population of 444 schoolchildren in total, 342 gave their consent. Ten children and their parents were excluded because they did not meet the inclusion criteria, so 332 children were included (75\% of the universe); 169 (51\%) were

TABLE 2. Criteria for the classification of parents and children based on their cholesterol level category

\begin{tabular}{|c|c|c|c|c|c|}
\hline \multicolumn{2}{|c|}{ Parents' category } & \multirow[t]{2}{*}{ Condition } & \multirow[t]{2}{*}{ Child's category } & \multirow[t]{2}{*}{ Condition } & \multirow[t]{2}{*}{ Classification } \\
\hline Mother/father 1 & Mother/father 2 & & & & \\
\hline \multicolumn{2}{|c|}{ If the category of mother/father 1 and 2 is: } & It is considered & And if the child is category & It is considered & And it is classified as \\
\hline A & A-B-C-D & Positive & $\mathrm{A}$ & Positive & True positive \\
\hline B-C & B-C & Negative & A & Positive & False positive \\
\hline $\mathrm{B}-\mathrm{C}$ & $\mathrm{B}-\mathrm{C}$ & Negative & B-C & Negative & True negative \\
\hline A & A-B-C-D & Positive & $\mathrm{B}-\mathrm{C}$ & Negative & False negative \\
\hline $\mathrm{D}$ & $A-B-C$ & Indefinite & A & Positive & Ruled out \\
\hline A & $A-B-C$ & Indefinite & $\mathrm{B}-\mathrm{C}$ & Negative & Ruled out \\
\hline D & D & Indefinite & A & Positive & Ruled out \\
\hline $\mathrm{D}$ & D & Indefinite & B-C & Negative & Ruled out \\
\hline
\end{tabular}

Note: Categories A, B, and C correspond to the cholesterol reference values in the pediatric and adult population shown in Table 1. Category D means "unknown" and indicates that the subject was not assessed because he/ she did not attend the blood draw visit. 
girls and $163(49 \%)$, boys. A total of 304 mothers and 206 fathers attended for the assessment.

The prevalence of cholesterol levels is shown in Table 3.

Cholesterol level (in mg/dL) in girls showed a mean and standard deviation (SD) of $164 \pm 28$, with a minimum of 110 and a maximum of 247, while in boys, the value showed a mean and SD of $163 \pm 28$, with a minimum of 103 and a maximum of 239 .

Cholesterol level in mothers showed a mean and SD of $183 \pm 40$, with a minimum of 99 and a maximum of 337, while in fathers, the value showed a mean and SD of $207 \pm 44$, with a minimum of 118 and a maximum of 342 .

The mean age of mothers and fathers was $36.2 \pm 6.4$ years and $41.0 \pm 7.2$ years, respectively.

Table 4 shows the results of the association between hypercholesterolemia in parents and their children and diagnostic tests.

Table 5 shows the results of the association between hypercholesterolemia in children and a positive FMH and diagnostic tests.

The multilevel regression analysis showed important and statistically significant effects of mother's and father's cholesterol level on their children's cholesterol level. Per every $10 \mathrm{mg} / \mathrm{dL}$ of increased average cholesterol in the mother, children's average cholesterol increased $2.9 \mathrm{mg} /$ $\mathrm{dL}$, and per every $10 \mathrm{mg} / \mathrm{dL}$ of increased average cholesterol in the father, children's average cholesterol increased $2.5 \mathrm{mg} / \mathrm{dL}$.

\section{DISCUSSION}

Numerous studies have been done in homozygous and heterozygous familial hypercholesterolemia, whose population prevalence is $1 / 1000000$ and from $1 / 250$ to $1 / 500$, respectively. ${ }^{19}$ Combined familial hypercholesterolemia, with a prevalence of 1-2 \%, is also of diagnostic interest. ${ }^{20}$ The objective of this study, and of previous ones, was to look for all types of hypercholesterolemia, including polygenic hypercholesterolemia, whose worldwide prevalence in the pediatric population ranges from $4 \%$ to $20 \%$ for cholesterol levels $\geq 200 \mathrm{mg} / \mathrm{dL}$.

The correlation observed between hypercholesterolemia in parents and their children is strong, with an OR of 6.40 and a $p$ value $<0.0001$, together with a high sensitivity and specificity and adequate values for the remaining diagnostic tests, except for PPV.

The association of FMH with hypercholesterolemia in children, in this case, resulted in an $\mathrm{OR}=1.86$, but no statistical

TABLE 3. Distribution of cholesterol levels among children, mothers and fathers

\begin{tabular}{|c|c|c|c|}
\hline & Children $(\mathrm{n}=332)$ & Mothers $(\mathrm{n}=304)$ & Fathers $(\mathrm{n}=206)$ \\
\hline Cholesterol level & $\mathrm{n}-\%$ & $\mathrm{n}-\%$ & $\mathrm{n}-\%$ \\
\hline High & $37-11.1$ & $20-6.6$ & $45-21.8$ \\
\hline Borderline high & $88-26.5$ & $82-27.0$ & $74-35.9$ \\
\hline Desirable & $207-62.3$ & $202-66.4$ & $87-42.2$ \\
\hline
\end{tabular}

TABLE 4. Correlation of blood cholesterol among children with a cholesterol level $\geq 200 \mathrm{mg} / \mathrm{dL}$ and one or both parents with hypercholesterolemia $\geq 240 \mathrm{mg} / \mathrm{dL}$ and diagnostic tests

\begin{tabular}{|c|c|c|c|c|c|c|c|}
\hline \multirow{2}{*}{$\begin{array}{l}\text { Outcome } \\
\text { measure }\end{array}$} & \multirow[b]{2}{*}{ Classification } & \multicolumn{3}{|c|}{ Children's cholesterol level $(n=200)$} & \multirow{3}{*}{ OR } & \multirow{3}{*}{$95 \% \mathrm{Cl}$} & \multirow{3}{*}{$p$} \\
\hline & & $\geq 200$ & $<200$ & Total & & & \\
\hline & & $\mathrm{n}$ & $\mathrm{n}$ & $\mathrm{n}$ & & & \\
\hline \multirow{5}{*}{$\begin{array}{c}\text { Parents' } \\
\text { cholesterol } \\
\text { level }\end{array}$} & One or both & 22 & 43 & 65 & \multirow{3}{*}{6.40} & \multirow{3}{*}{$(2.85-14.48)$} & \multirow{3}{*}{$<0.0001$} \\
\hline & with $\geq 240$ & & & & & & \\
\hline & None $\geq 240$ & 10 & 125 & 135 & & & \\
\hline & \multirow[t]{4}{*}{ Total } & 32 & 168 & 200 & & & \\
\hline & & \multicolumn{6}{|c|}{ Diagnostic tests } \\
\hline PPA & & Sensitivity & Specificity & PPV & NPV & $\mathrm{LR}+$ & LR- \\
\hline$(33 \%)$ & & $(69 \%)$ & $(74 \%)$ & $(34 \%)$ & $(93 \%)$ & 2.69 & 0.42 \\
\hline
\end{tabular}

PPA: percentage of the population to be assessed; PPV: positive predictive value; NPV: negative predictive value; LR+: positive likelihood ratio; LR-: negative likelihood ratio; CI: confidence interval. 
association was observed and diagnostic tests showed weaker values than parental hypercholesterolemia.

The two predictive outcome measures detected 22 out of 32 children with hypercholesterolemia, i.e., they have the same sensitivity $(69 \%)$. In spite of the numerical match, only 13 children were screened by both criteria.

The mean cholesterol level in children was slightly lower than that observed in 2009 (164 versus 168).

Results of the multilevel regression analysis are consistent with the data in the contingency tables in terms of the correlation of blood cholesterol between parents and their children.

Two situations may alter the predictive power of parental hypercholesterolemia: the fact that parents are not screened for the presence of diseases or other factors that may cause secondary hypercholesterolemia and the relative youth of parents (mean of 36.2 years old for mothers and of 41.0 for fathers), considering that the mean cholesterol level increases with age.

A strength of this study -and of our three previous epidemiological studies from 1997, 2003, and $2009-{ }^{9,15}$ is the large sample size $(75 \%)$. The percentage of mothers who gave their consent was also very high and, although the percentage of fathers was lower, it was acceptably good.

In a cascade screening study to look for familial hypercholesterolemia conducted in the United Kingdom, ${ }^{20} 97 \%$ of children were tested, while $5 \%$ of adults refused to participate and $59 \%$ did not respond. This would seem to indicate that parents' concern for their children is greater than that for themselves.

Few studies of this kind have been done. The Family Study, conducted in 1980, found a positive, strongly significant correlation in the blood cholesterol of parents and their biological children, which was related to genetic factors. ${ }^{21}$

It may be assumed that a detection strategy based on this concept may be extrapolated to the entire blood relative unit and, therefore, selective screening may be combined with cascade screening.

A gold standard method to detect a disease or a factor leading to a disease is one with a high sensitivity and specificity. A third indicator would be its moderate or low cost so that it may be implemented in countries with a low health budget so as to optimize expenditure.

The methods proposed to screen for hypercholesterolemia in children include the following:

- Cascade screening: To detect individuals with familial hypercholesterolemia. A metaanalysis by Morris et al. considered that this was a good but inadequate strategy to identify new index cases, with a low sensitivity and high cost. ${ }^{22}$

- Universal screening: It is highly sensitive and specific, but expensive and hard to implement. The SAP consensus proposes to screen all children when they first start primary school. Wald et al. ${ }^{23-25}$ conducted a small-scale experimental study and a largescale study that assessed 10000 children to look for familial hypercholesterolemia and concluded that screening was feasible and effective at 36 months old, together with children's immunization schedule, and that parents of children with a positive mutation or high cholesterol levels may then be tested. For developing countries, this is a very expensive approach.

TABLE 5. Correlation of blood cholesterol among children with a cholesterol level $\geq 200 \mathrm{mg} / \mathrm{dL}$ and a positive family medical history and diagnostic tests

\begin{tabular}{|c|c|c|c|c|c|c|c|}
\hline \multirow{2}{*}{$\begin{array}{l}\text { Outcome } \\
\text { measure }\end{array}$} & \multirow{3}{*}{ Classification } & \multicolumn{3}{|c|}{ Children's cholesterol level $(n=200)$} & \multirow{3}{*}{ OR } & \multirow{3}{*}{$95 \% \mathrm{Cl}$} & \multirow{3}{*}{$p$} \\
\hline & & $\geq 200$ & $<200$ & Total & & & \\
\hline & & $\mathrm{n}$ & $\mathrm{n}$ & $\mathrm{n}$ & & & \\
\hline \multirow{4}{*}{$\begin{array}{l}\text { Family } \\
\text { medical } \\
\text { history }\end{array}$} & Positive & 22 & 91 & 113 & & & \\
\hline & Unknown/negative & 10 & 77 & 87 & 1.86 & $(0.84-4.11)$ & 0.1272 \\
\hline & Total & 32 & 168 & 200 & & & \\
\hline & & \multicolumn{6}{|c|}{ Diagnostic tests } \\
\hline PPA & & Sensitivity & Specificity & PPV & NPV & LR+ & LR- \\
\hline$(57 \%)$ & & $(69 \%)$ & $(46 \%)$ & $(19 \%)$ & $(89 \%)$ & 1.27 & 0.68 \\
\hline
\end{tabular}

PPA: percentage of the population to be assessed; PPV: positive predictive value; NPV: negative predictive value; LR+: positive likelihood ratio; LR-: negative likelihood ratio; CI: confidence interval. 
Some kind of universal screening has been implemented in some countries, like Slovenia, where all children with a positive FMH have their cholesterol level measured at 5 years old; if their value is high, a lipid profile is done and the family is tested afterwards. They also focus on familial hypercholesterolemia but they have stated that FMH is not reliable enough to identify cases. ${ }^{26}$

- Selective screening: To this date, this is the most widely accepted method. Selective screening has been suggested by the AAP and the SAP based on FMH, but the specificity is low and the cost high.

The 2009 study $^{15}$ showed a statistically significant correlation between hypercholesterolemia and FMH (OR: 2.20, $95 \%$ CI: $1.18-4.13$ and $p=0.014)$ and acceptable diagnostic tests (sensitivity $=65 \%$, specificity $=37 \%, \mathrm{PPV}=17 \%, \mathrm{NPV}=89 \%$, $\mathrm{LR}+=1.16$, and $\mathrm{LR}-=0.71$ ). To screen that $65 \%$ of children (33 out of 51) with hypercholesterolemia, it would be necessary to assess $49 \%$ of the population (189 out of 382), which, in this study, we defined as PPA. If the calculation is done by adding the children with a positive FMH and those with an unknown FMH, as suggested by current consensuses, the correlation disappears and most diagnostic tests show weaker values.

Because of this, both at that time and in this study, only a positive FMH was considered a screening criterion. The PPA based on the FMH would be $57 \%$. This means that if FMH was used as a selective screening criterion in this study population, $57 \%$ of the population (113 out of 200) should have been assessed, whereas if parental hypercholesterolemia was used, only $33 \%$ of the population (65 out of 200) should have required assessment. This would indicate that, besides diagnostic tests, parental hypercholesterolemia is more effective as a predictor and would translate into lower screening costs.

Based on these findings, an idea-project called "Hypercholesterolemia screening in children and adolescents at the pharmacy office" is being developed because this is where patients diagnosed with hypercholesterolemia obtain medicine and the most commonly visited health care site by patients in general. ${ }^{27}$

Adequate outcomes were achieved by a virtual trial of this idea-project. Approximately $30 \%$ of adult and pediatric patients with hypercholesterolemia and other $30 \%$ of adult and pediatric patients with slightly elevated cholesterol levels were detected..$^{28}$
The pharmacy and the health care team working in this field may act in a joint and systematic manner to develop registers of patients with homozygous and heterozygous familial hypercholesterolemia, which is a nationwide and worldwide demand.

\section{CONCLUSION}

Parental hypercholesterolemia showed a positive and strongly significant association with hypercholesterolemia in children and acted as an adequate predictor. A positive FMH was not associated with hypercholesterolemia in children and showed a smaller predictive power than parental hypercholesterolemia.

\section{Acknowledgments}

We would like to thank the teachers, administrative staff, and other personnel of the schools where the study took place.

Also, to the companies and institutions that helped with material and financial resources.

To the more than 30 collaborators - physicians, teachers, biochemists, nurses, administrative staff, and other specifically-trained officers- who voluntarily helped with the field work.

To Fernando Torres, M.D., for his appropriate suggestions.

And to the people of Jovita.

\section{REFERENCES}

1. Enos WF, Holmes RH, Beyer J. Coronary disease among United States soldiers killed in action in Korea; preliminary report. J Am Med Assoc. 1953;152(12):1090-3.

2. Enos WF, Holmes RH, Beyer J. Landmark article, July 18, 1953: Coronary disease among United States soldiers killed in action in Korea. Preliminary report. By William F. Enos, Robert H. Holmes and James Beyer. JAMA. 1986; 256(20):2859-62.

3. Stary HC, Chandler AB, Dinsmore RE, et al. A Definition of Advanced Types of Atherosclerotic Lesions and a Histological Classification of Atherosclerosis: A Report From the Committee on Vascular Lesions of the Council on Arteriosclerosis, American Heart Association. Circulation. 1995; 92(5):1355-74.

4. Strong JP, Malcom GT, McMahan CA, et al. Prevalence and Extent of Atherosclerosis in Adolescents and Young Adults. JAMA. 1999; 281(8):727-35.

5. McGill HC Jr, Geer JC, Strong J. Natural history of human atherosclerotic lesions. In Sandler M, Bourne G (eds.). Atherosclerosis and its origin. New York: Academic Press; 1963.Page.39-65.

6. The Lipid Research Clinics Program. The Lipid Research Clinics Coronary Primary Prevention Trial Results: I. Reduction in incidence of coronary heart disease. JAMA. 1984; 251(3):351-64.

7. The Lipid Research Clinics Program. The Lipid Research Clinics Coronary Primary Prevention Trial Results: II. The relationship of reduction in incidence of coronary heart disease to cholesterol lowering. JAMA. 1984; 251(3):365-73. 
8. Expert Panel on Integrated Guidelines for Cardiovascular Health and Risk Reduction in Children and Adolescents; National Heart, Lung, and Blood Institute. Expert panel on integrated guidelines for cardiovascular health and risk reduction in children and adolescents: summary report. Pediatrics. 2011; 128(Suppl 5):S213-56.

9. LubetkinA, RobledoJ, Siccardi L, RodriguezMI.Prevalencia de hipercolesterolemia en la población estudiantil de una localidad de la provincia de Córdoba. Arch Argent Pediatr. 2005; 103(4):298-304.

10. Pedrozo W, Bonneau G, Castillo Rascón M, etal. Valores de referencia y prevalencia de las alteraciones del perfil lipídico en adolescentes. Arch Argent Pediatr2010;108(2):107-15.

11. Rosillo I, Pituelli N, Corbera M, et al. Perfil lipídico en niños y adolescentes de una población escolar. Arch Argent Pediatr 2005; 103(4):293-7.

12. American Academy of Pediatrics. Committee on Nutrition. Cholesterol in childhood. Pediatrics 1998; 101(1 Pt 1):141-7.

13. Grupo de Hipercolesterolemia, Sociedad Argentina de Pediatría. Consensosobrefactores de riesgo de enfermedad cardiovascular en pediatría. Hipercolesterolemia. Arch Argent Pediatr 2005; 103(4):358-66.

14. Comité de Nutrición, Sociedad Argentina de Pediatría. Consenso sobre manejo de las dislipidemias en pediatría. Arch Argent Pediatr 2015; 113(2):177-86.

15. RobledoJA, Siccardi LJ. Relación entre factores genéticos y medioambientales y la hipercolesterolemia en niños. Arch Argent Pediatr 2016; 114(5):419-25.

16. Bentz M, Magnette J. Hypocholestérolémie au cours de la phase aiguë de la réaction inflammatoire d'origine infectieuse. À propos de 120 cas. Rev Med Interne 1998; 19(3):168-72.

17. Haney EM, Huffman LH, Bougatsos C, et al.Screening and treatment for lipid disorders in children and adolescents: systematic evidence review for the US Preventive Services Task Force. Pediatrics 2007; 120(1):e189-214.

18. National Cholesterol Education Program. Detection, Evaluation, and Treatment of High Blood Cholesterol in Adults (Adult Treatment Panel III): Full Report. Bethesda: NIH Publication; 2001;01-3670:1-284.
19. Cuchel M, Bruckert E, Ginsberg HN, et al. Homozygous familial hypercholesterolaemia: New insights and guidance for clinicians to improve detection and clinical management. A position paper fromthe Consensus Panel on Familial Hypercholesterolaemia of the European Atherosclerosis Society. Eur Heart J 2014; 35(32):2146-57.

20. Mata P, Alonso R, Ruíz-Garcia A, et al. Hiperlipidemia familiar combinada: documento de consenso. Aten Prim (Barc) 2014; 46(8):440-6.

21. Morrison JA, Laskarzewski PM, Khoury $\mathrm{P}$, et al. Intrafamilial associations of cholesterol and triglyceride among related and unrelated household members. Clin Genet 1980; 18(5):321-8.

22. Morris JK, Wald DS, Wald NJ. The evaluation of cascade testing for familial hypercholesterolemia. Am J Med Genet A 2012; 158A(1):78-84.

23. Wald DS, BestwickJP, Wald NJ. Child-parent screening for familial hypercholesterolaemia: screening strategy based on a meta-analysis. BMJ 2007; 335(7620):599.

24. Wald DS, Kasturiratne A, Godoy A, et al. Child-parent screening for familial hypercholesterolemia. J Pediatr 2011; 159(5):865-7.

25. Wald DS, BestwickJP, Morris JK, et al.Child-ParentFamilial Hypercholesterolemia Screening in Primary Care. N Engl J Med 2016; 375(17):1628-37.

26. Klančar G, Grošelj U, Kovač J, et al. Universal screening for familial hypercholesterolemia in children. J Am CollCardiol. 2015; 66(11):1250-7.

27. Robledo J. Poster Presentation: Proposal for development of a new professional pharmaceutical service in the community: Screening of hypercholesterolemia in children and youth at the pharmacy office, with subsequent intervention. In 77th FIP World Congress of Pharmacy and Pharmaceutical Science. 2017 Set 10-14; Seoul, Korea.

28. Robledo JA, Real JP, Gimenez-Kairuz A, Vargas A. Poster presentation: Screening of hypercholesterolemia in children at the pharmacy office, with subsequent intervention. Virtual test to evaluate efficacy of proposal. In 77th FIP World Congress of Pharmacy and Pharmaceutical Science. 2017 Set 10-14; Seoul, Korea. 